\title{
Attitude of Nursing Students Towards Work in the Clinical Learning Environment
}

\author{
Chiamaka Rosemary Anagor ${ }^{1}$, Felicia Ekwok Lukpata ${ }^{2}$, Jennifer Nkeiruka Ikechukwu-Okoroezi ${ }^{3}$ \& May \\ Ulunma Obiora $^{4}$ \\ ${ }^{1}$ Department of Nursing Science, University of Nigeria, Enugu Campus, Nigeria \\ ${ }^{2}$ Department of Nursing Sciences, University of Calabar, Cross River State, Nigeria \\ ${ }^{3}$ Department of Nursing Science, Abia State University Uturu, Nigeria \\ ${ }^{4}$ University of Nigeria Teaching Hospital (UNTH), Ituku Ozalla Enugu, Enugu State, Nigeria \\ Correspondence: Chiamaka Rosemary Anagor, Department of Nursing Science, University of Nigeria, Enugu \\ Campus, Nigeria.
}

Received: February 12, 2021

Accepted: March 11, 2021

Online Published: March 22, 2021

doi:10.20849/ijsn.v6i1.855

URL: https://doi.org/10.20849/ijsn.v6i1.855

\begin{abstract}
Introduction: Exposure to the clinical learning environment is indispensable for the nursing students as it provides experiences which are basic and significant to the development of professional skills as well as bridge the theory-practice gap. Despite the importance of clinical learning, nursing students' attitudes in the clinical environment has been a concern.

Purpose: This paper reviewed the attitude of nursing students towards work in the clinical learning environment.

Method: Electronic searches using scholarly databases were employed and only significant articles that met the review objective were utilized.

Findings: This review revealed that there is a high rate of unauthorized student nurses' absenteeism as majority are absent from clinical work without permission. There is also an appalling display of lateness behavior as students arrive at work after the scheduled time. Interestingly, most students are willing to carry out procedures while some are nonchalant due to the stressful and anxiety provoking tasks. Student nurses felt that there is an unspoken comparison, discrimination and disrespect displayed by their seniors and medical colleagues towards them.

Conclusion: There is overwhelming evidence from literature supporting the negative attitudes of nursing students in the clinical environment. It was therefore recommended that students should be psychologically prepared in their schools before exposure to the clinical environment. There should be an effort to build students' self-esteem and professional self-concept by the relevant authorities. Finally, to bridge the rift between inter-professionals, there is need for more social interaction opportunities where everyone will value what each member contributes to the team.
\end{abstract}

Keywords: nursing student's attitude, attendance to work, clinical environment, punctuality, inter-professional relationship, respect for seniors

\section{Introduction}

\subsection{Background of the Study}

Nursing education consist of both theoretical and practical aspects which are weighted on an equal scale. For nursing students to be adequately prepared for professional practice, they must be comprehensively prepared theoretically and practically (hands-on Patients) as just the theoretical preparation alone is inadequate (Aragaw, Sinishaw, Daba \& Mekie, 2019; Jamshidi, Molazem, Sharif, Torabizadeh, \& Kalyani 2016). Nursing is unarguably more of a practice-oriented discipline which implies that knowledge gained during practical placement prepares the student nurses more professionally than the theoretical knowledge gained in the classroom environment (Mugoh \& Kamau 2020; Awuah-Peasah, et al, 2013; Mamaghani, et al, 2018). However, for students' nurses to be fully equipped for professional practice, both aspects of the training must be given equal attention so as to eliminate the theory-practice gap which has been a challenge in nursing education. 
According to Tiwaken, Caranto and David (2015), student nurses must be exposed to both facets equally and one of the best ways of realizing this is by giving them the opportunity to put what they have learnt in the classroom into practice through clinical placement in the various clinical settings such as hospitals wards, primary health care institutions, special clinics, communities and nursing homes, comprehensive care clinics/patients support clinics, maternal and child welfare clinics etc. under the strict direction and supervision of faculty members, instructors, preceptors and nurse clinicians (Mugoh \& Kamau 2020; Nabolsia, et al, 2012).

Clinical exposure contributes to the overall academic preparation of the student for the nursing profession, and provide the student with opportunity to interact with patients/clients and other health team members; learn the ethics of the profession, practice nursing skills on humans, observe role models and reflect upon what he/she has seen, heard, sensed and done (Kapucu \& Bulut, 2011). Bjørk, Berntsen, Brynildsen and Hestetun (2014) assert that legally, exposing nursing students to practice in a clinical environment is a requirement to ensure fitness to practice as a nurse while Lapeña-Moñux, et al (2016) also opined that clinical placements for undergraduate nursing students provide experiences which are basic and significant to the development of student professional skills and development. It enhances their ability to marry theoretical knowledge with cognitive, affective and psychomotor skills required in client care. Clinical placement also facilitate students' acquisition of problem-solving abilities that will enable them function as professionals in the various health care settings (Kapucu \& Bulut, 2011; Nabolsia, et al, 2012). Agu (2017) posit that, the cardinal purpose of clinical placement in nursing education is to prepare nurses to meet the health care needs of the society they serve. Students' perception of clinical work vary, some view clinical placements as the most important aspect of their training while others see it as stressful but rewarding (Bjørk et al, 2014).

Despite the importance of clinical experience, posting or placement in acquisition of nursing skills, numerous studies have revealed challenges in nursing students' attitude towards clinical work/placement (Jamshidi, et al, 2016; Rajeswaran 2016; Drateru, 2019; Agu, 2017). According to Aragaw, et al (2019) \& Mugoh and Kamau (2020), attitudes plays a principal role in guiding human behavior toward achieving goals. The attitudes of nursing students toward clinical work has been noted to be a topic of interest for research because whatever attitude students display to clinical work, be it the positives or negatives, it can either enhance effective clinical learning or mar the acquisition of essential clinical skills (Mugoh \& Kamau, 2020). Aragaw et al (2019) reported negative attitudes towards clinical work/posting among nursing students. According to Aragaw et al (2019), $57.1 \%$ of the nursing students had negative attitudes towards clinical practice while only $42.9 \%$ had a positive disposition towards clinical work. Attitudes exhibited range from punctuality to work resumption, willingness to carry out nursing procedures, relationship with inter-professional students and respect for senior colleagues and nurse clinicians.

Attitudes of nursing students towards clinical work have been attributed to some factors. Bjørk et al (2014) posit that the attitude and perception of nursing students towards clinical posting may be "related to a lack of qualified nursing staff that can cover the students' needs for supervision". Other determinants of nursing student attitudes to clinical work has been identified as unpleasant hard work in the hospital, working on holidays, lack of respect for work, and loss of interest in what they do (Awuah-Peasah et al, 2013; Koushali et al, 2012). Aragaw et al (2019) also asserts that, nursing Students' attitudes towards clinical work may be influenced by the clinical learning environment, student-staff interaction, attitude of preceptors and, the availability of necessary equipment in a hospital setting amongst others. All these and more affect their willingness to attend to work, the quality of work they provide and it also contributes to mental and occupational burnout syndrome alongside feelings of helplessness, frustrations and discouragement (Koushali et al, 2012).

In today's world, nursing students on clinical placements make up a huge percentage of the nursing workforce in our health care institutions and are trained to graduate as professionals who will be employed in the healthcare system where they will be entrusted with human lives. Nursing students' attitudes to clinical work while in training determines their abilities and capabilities in carrying out professional task, duties and responsibilities as future nurses. This concern gave impetus to this review on nursing students' attitudes to clinical work. Specifically, nursing students' attendance to work, willingness to carryout nursing procedures, Peers/inter professional relationship and respect for seniors will be discussed in this review.

\subsection{Objectives}

The objectives of this review study are to:

i. Explore nursing students attitude to work attendance

ii. Examine nursing students willingness to carry out nursing procedures 
iii. Discuss nursing students inter professional relationship

iv. Discuss nursing students respect for senior colleagues

\section{Method}

A thorough narrative review of the literature on attitude of nursing students towards work in the clinical learning environment was conducted using scholarly databases from Google Scholar, Semantic Scholar and Google search engines. The researchers employed various combinations of appropriate search terms, key words and phrase combinations such as 'nursing students attitudes, attendance to work, clinical environment, punctuality, inter-professional relationship, respect for seniors, clinical practice' etc. Relevant articles which met the review objectives was retrieved and utilized in the study. In addition, supplementary articles gotten from references of selected articles which were related to the research topic and objective was also consulted.

\section{Findings}

\subsection{Attendance to Work}

Nursing students are expected to regularly attend work as they are scheduled except on their official off days. Regular attendance to work provides them with the opportunity to be supervised, taught and corrected by clinical instructors, preceptors and nurse clinicians. It reduces the phobia of carrying out procedures on humans as they practice hands-on-patients as against the models used in nursing laboratories. However, regular attendance to work has been a challenge despite an expected percentage of attendance set by most training institutions (Abdelrahman \& Abdelkader, 2017; Nawaz, Hussain, Sarwar, Afzal, Gilani, 2018). Chukwu et al (2017) argue that student nurse attendance during training is mandatory because it is a crucial requisite in the training and influences the learning outcomes and professionalism. Middlesex University (2011) stipulate that, in order to meet the requirements of the Nursing and Midwifery Council (NMC) students on Pre-registration, nursing programmes must attain a minimum of 4600 curricula hours; a minimum of 2300 of which are theory hours and 2300 are practice hours. According to Magobolo and Dube (2019), the South African Nursing Council (SANC) stipulate that nursing students must attain $80 \%$ of the required hours for both theory and practice to be eligible for the professional qualifying examination. They reiterate that "unauthorized student nurse absenteeism, especially in the clinical areas, has become an increasing problem in nursing education institutions and in the Universities". Absenteeism from the classroom and clinical practice environment negatively affects nursing students' academic performance, acquisition of nursing skills and increase their length of study years and concluded that "absenteeism amongst student nurses in the nursing schools is relatively high (Nawaz et al, 2018).

The negative attitude of nursing students towards attendance to work has been observed by several studies affirming a high rate of absenteeism. A study by Faiza (2015) conducted in the faculty of nursing sciences, University of Khartoum- Sudan revealed a $29.4 \%$ prevalence rate of absenteeism among nursing students while in the Department of Nursing, University of Maiduguri, Nigeria, Chukwu et al (2017) reported a cluster mean of 2.99 for prevalence of absenteeism among nursing students. In a study by Awuah-Peasah et al (2013) to determine the perspective of 100 practicing nurses on students' attitude toward clinical work, $60 \%$ of the respondents reported that students were absent from clinical work without permission.

A study was carried out at Kwazulu College of nursing to find out the causes and effect of student nurses absenteeism (Singh, 2015), It was noted that the nursing students showed an increased level of absenteeism and continuous absenteeism could result in consequences for the student such as demotion, extension of training or termination of students from the program (Singh, 2015). It is worthy of note that if this punishment becomes a frequent occurrence, it would result in fewer student nurses completing the training and therefore result to a shortage of professional nurses. Moreover, nursing students are the future of nursing work force (Natan, Zilberstein, \& Alaev, 2015) and nurses are the health professionals with whom patients and clients interact with more frequently than any other health service professional, therefore retaining student nurses in training is imperative as they will increase the pool of trained/professional nurses (Singh, 2015).

\subsection{Punctuality to Work}

Punctuality is important in all work places and the nursing job is not exempted. Punctuality denotes promptness and regularity to work resumption time excluding work-off days. Nursing students on clinical placements are expected to be punctual to work and to adhere to the rotational schedules to enhance full participation in all client care activities for the day. Nursing students who are not punctual miss out on the opportunity to observe some of the clinical procedures carried out on the patients by the health care team and may also miss the opportunity to perform those procedures (Awuah-Peasah et al, 2013). In spite of this, literature has it that 
majority of the nursing students reported late to clinical work (Awuah-Peasah et al, 2013). Lateness behavior can be described as arriving at work after the scheduled time (Kasu, 2014). In a study by Awuah-Peasah et al (2013) to determine the perspective of 100 practicing nurses on students' attitude toward clinical work, $63 \%$ of the respondents said nursing students reported late to work. When asked what time student nurses' report daily to work, $19 \%$ indicated that student nurses reported 30 minutes before the start of shift, $26 \%$ said students reported at the exact start of the shift, $41 \%$ insisted that students reported 30 minutes late, while $14 \%$ responded that students reported more than one hour late. The researchers noted that if students are allowed to cultivate the habit of reporting late to clinical work, they are also likely going to report late to work when they start practicing.

Several reasons for lateness to work have been identified by studies which include; low morale attributed to lack of reward, workplace mistreatment, illness, arrogance, emergencies, household crisis, poor weather conditions, car accidents or other minor circumstances such as traffic jams, car problems or public transit issues (Kasu, 2014). Stress due to work overload has also been implicated as a cause of lateness as most students see clinical placement as a very stressful experience (Singh, 2015; Mlek, 2011). When students are stressed due to heavy and demanding workloads, it can have a significant impact on their ability to accomplish tasks, they may then begin to avoid work and deliberately resume late for work thereby contributing towards a decreased work performance/output (Singh, 2015). Kasu (2014) identified lack of recognition and appreciation, duration of working hours and physical conditions of the working environment as reasons to the rise in lateness and absenteeism to work. Again, Mamaghani et al (2018) in their study attributed lateness and absenteeism to lack of educational opportunity such as the non- availability of novel cases in the inpatient wards and outpatient clinics and, lack of opportunity to put into practice knowledge and skills acquired. They posit that these factors decrease motivation to learn as students considered their presence in the clinical environment as not necessary. Notwithstanding, lateness to work ought not to be encouraged as it destabilizes the establishment's day goal, bringing about tremendous economic and psychological consequences on the level of output and productivity of the organization (Kasu, 2014).

\subsection{Willingness to Carry Out Nursing Procedures}

Nursing procedures are standardized procedures used by nurses to achieve a high level of patient care, keeping nurses on task, and enabling them to ensure that patients are getting the utmost care they need (McMahon, 2020). Procedures includes actions involving controlled acts, non-controlled acts, and any action or activity nurses use in the course of providing client care (College of Nurses of Ontario, 2018). Adhering to standardized procedures is very crucial because they aid the nurse in establishing priorities of care, which may entail concentrating on critical issues first before moving to less serious medical problems (McMahon, 2020). Furthermore, these procedures also act as a checklist which can be used to ascertain that even the tiniest bit of nursing care has been instituted for the patient and in the right proportion; they also direct the nurse on how to perform administrative duties (e.g. charting), as well as dictate the number of patients a nurse can care for at a time plus the maximum number of hours a nurse can work in a day (McMahon, 2020). Nursing procedures basically help to establish and maintain a therapeutic nurse-client relationship which is critical in implementing and evaluating client's plan of care (College of Nurses of Ontario, 2018).

One of the duties of the student nurse on clinical work is to carry out nursing procedures on patients as scheduled by the ward manager under the supervision of registered nurses. Although, according to the South African Nursing Council (2013) as cited by Mukumbang \& Adejumo (2014), nursing students are allowed to perform only nursing procedures they have been taught by nurse educators or clinical instructors, and only if they have the necessary knowledge, skill and judgment to perform these acts as adjudged by their clinical supervisors. A study by Mukumbang and Adejumo (2014) on patients' experiences of being nursed by student nurses revealed that majority of the patients were comfortable with being nursed by students and acknowledged that the students did well and showed willingness to work. One of the respondents expressed "To tell the truth, most of the time I feel very comfortable... and they also help you when you don't understand something..." Most of the respondents in the study also stated that student nurses were very supportive, had a helpful attitude and expressed willingness to be of service to the patients. Similarly, Debyser, Grypdonck, Defloor, and Verhaeghe (2011), revealed that patients sincerely appreciate the work nursing students carry out, specifically those students who are authentic, spontaneous and sensitive. Mossop and Wilkinson (2006) in a study of elderly patients' perception of student-rendered care observed that the patients appreciated the efforts of the students and the work that they do. The clients expressed a tremendous positive experience as emergent themes indicated that the patients enjoyed the extra care, attention, and the increased social opportunities the nursing students provided. In Awuah-Peasah et al (2013), 59\% of the respondents agreed that students' nurses were committed to work and 
concluded that when student nurses are committed to their work, they will most likely provide the best quality of care to their patients (Awuah-Peasah et al, 2013).

Despite these positive experiences, literature has also revealed that nursing students also display nonchalant and negative attitude to clinical work as some consider nursing task stressful and anxiety provoking (Jamshidi et al, 2016; Mugoh \& Kamau, 2020; Mlek, 2011). Mukumbang and Adejumo (2014) reported that some patients complained of poor professional behavior and negative attitudes displayed by the student nurses when they deliver their care. Poor professional attitude and behavior is sometimes evident in the way they talk, relate and respond to the needs of the patients during their caring sessions. Jamshidi et al (2016), stated that the young age of nursing students, their social and emotional lack of experience and fear of contracting threatening health issues may lead to stress, discouragement and decrease their participation in clinical activities (Baraz, Memarian \& Vanaki 2015). Kok, Guvenc and Kaplan (2018) study on nursing students' knowledge, attitude and willingness to care for HIV/AIDS revealed that lack of knowledge, stigma attached to the disease and the fear of possibly becoming infected made many nursing students hesitant in providing care for these patients. Other reasons for nursing students' unwillingness to participate in nursing work include lack of competency in carrying out some nursing procedures which students attribute to insufficient time to practice and repeat these skills before being assigned to go for clinical work (Rajeswaran, 2016; Jamshidi et al, 2016; Mukumbang \& Adejumo, 2014). Although the students agreed that they learned the fundamentals of nursing in classrooms and practice rooms, it seems not sufficient especially when they are faced with actual patients, thus making them anxious (Jamshidi et al, 2016). It is worthy of note that the after-effect of this feeling of incompetency, brings about fear and the students become afraid of making mistakes and hurting the patient thereby increasing their unwillingness to participate in clinical work (Rajeswaran, 2016).

The theory-practice gap in nursing education has been identified as a contributor to the negative attitudes of nursing students to clinical placement. Nursing education is basically grounded on a close relationship between theoretical teaching and practical experience (Esmaeili, Cheraghi, Salsali, \& Ghiyasvandian, 2014). However, Agu (2014) and Rajeswaran (2016) report that students expressed that the instructions in the clinical environment differ from what they were taught in the classroom. They therefore find themselves torn between what was supposedly 'the right procedure' taught by the nurse educators and what is actually being practiced by the practicing nurses in the clinic, bringing about conflicts and confusion. Agu (2014), identified some factors responsible for the theory-practice gap as 'lack of experienced and knowledgeable teachers to supervise and teach the students in the clinical areas, limited procedures in the hospitals for students to practice, inexperienced nurses working in the hospitals, lack of update in knowledge of current trends in nursing practice (Agu, 2014).

Again, limited nursing procedures in the clinical environment contribute to student lack of enthusiasm in clinical work. Deepa and Kandasamy (2015) assert that since students were just limited to basic procedures and restricted from practicing other skills, they become uninterested in clinical work because they feel that nursing is 'not really professional' in that sense and lacks variety in procedures. Students complained that, even when they are taught the ideal nursing care in the class, in the clinical environment their preceptors and instructors concentrate on doing the functional work while delegating students to mostly bed making (Drateru, 2019; Nabolsia et al, 2012). This is a critical issue that deserves attention if the enthusiasm in nursing work of the future generation of nurses is to be maintained and sustained. Baraz et al (2015) in their study also identified the challenge of non-supportive relationship of the clinical nurses as a cause of student nurses' negative attitudes to clinical work. They report that students attributed their disenchantment with clinical work to the harshness, behavioral and verbal violence meted out to them which instils fear and anxiety, makes them lose motivation, makes them feel isolated, withdrawn and invariably makes them unwilling to attend clinical placement.

\subsection{Nursing Students Inter Professional Relationship}

Inter-professional students in this context refer to students in other healthcare professions. They include but not limited to students doctors, medical laboratory scientist, radiographers, anatomists, physiotherapist, pharmacists etc. It is imperative that these groups of health care providers learn to work together right from their period of training as they basically would work together after graduation with a common goal of client welfare. There is scarce evidence in literature on student nurses close relationship with students from other healthcare professions except for student doctors. Evidence shows the poor quantity and quality of the interactions between medical students and nurses, affecting negatively their collaboration right from training (Visser, Ket, Croiset \& Kusurkar, 2017). Over time, there has been an unspoken comparison between nursing and medicine; upholding medicine as a superior major while downsizing nursing as inferior which in turn has a devastating effect on nursing students' as it violates their personal dignity and give them a sense of professional inferiority (Jamshidi et al, 2016). Inferiority complex has been noted as one of the challenges resulting to students' negative attitudes to clinical 
work. In Jamshidi et al's (2016) qualitative study to elicit the challenges of nursing students in the clinical learning environment, respondents complain of feeling inferior which has reduced their sense of self-confidence and affected inter-professional peer relationship. This is in line with Edwards, Burnard, Bennett and Hebden (2010) study on stress and self-esteem in nurses which showed that low self-confidence is one of the nursing students' major problems.

One of the activities that should have improved relationship between inter-professional students is the general ward rounds. Awuah-Peasah et al (2013) assert that about $80 \%$ of nursing students partook in general ward rounds, however, majority of the students do not ask questions and remain mute, even though this was an excellent opportunity for them to relate and interact with their peers in the medical field. Duchscher cited in Awuah-Peasah et al (2013) has stated that the non-readiness of nursing students to interact with others poses a serious threat to the nursing profession as nurses do not work in isolation but as a team to enhance patients' wellbeing. All these have inadvertently soured the supposedly good relationship student nurses should have had with their counterparts as they struggle with inferiority complex, intimidation and low self-confidence. Another important and disturbing concern raised by nursing students which hinders their interaction with other student healthcare professionals is the issue of discrimination. Intense discrimination has been reported especially in the distribution of welfare resources and educational facilities in the clinical settings (Mamaghani et al, 2018). Nursing students stated that they do not have welfare facilities such as resting rooms or suitable dressing rooms like the medical students, neither were they allowed to make use of educational resources, such as the library, Internet, and training classes in the clinical environment as these resources were only available to the medical students. This experience of discrimination between medical and nursing students affects peer relationship in the clinical environment (Mamaghani et al, 2018). This has basically resulted in a decline in educational motivation, professional attitude, decreased provision of quality care, jealousy of other students, increased tendency to leave nursing and reduced interest in attendance to clinical postings (Mamaghani et al, 2018).

According to Prentice et al (2015) a rift exists between nursing and medical students even in the early stages of their programs where nursing students perceive that they were not valued and student doctors act like they are infallible, to the extent of "humiliating student nurses" (Altiok \& Üstun, 2013). To surmount this rift, there is need for more social interaction opportunities where both parties can come together to interact, address and learn about each other's role function, hence the suggestion by some authorities to include Inter-professional Education (IPE) in the curriculum (Sumiyoshi, Yokono, Kawachi \& Suzuki, 2020). Since it cannot be denied that a good working relationship is paramount to providing patient care that is really patient centered, then this chasm that exists between disciplines needs to be bridged by enhancing understanding of each health care provider's roles \& responsibilities and valuing what each member contributes to the team (Prentice et al, 2015).

\subsection{Nursing Students Respect for Senior Colleagues}

Respect is an attitude directed towards someone based on his/her qualities that make him/her respect-worthy alongside cognitive, affective and behavioural components (Clucas \& Chapman, 2014). Respecting a person entails treating them as persons of worth, valuing their humanity by being sensitive to their physical and psychological integrity and treating them as autonomous and rational human beings (Clucas \& Chapman, 2014). Student nurses are expected to show respect to nurse clinicians, because not only is the clinicians ahead of them in the profession, but also, most of these nurse clinicians are older and more experienced than them. Kirabira (2018) opine that "junior nurses should respect their seniors so that they can seek knowledge from them". When one respects the source of information, there is a high likelihood of developing a positive attitude towards it and then uses it effectively. Showing respect to nurse clinicians' means that they hold them in high esteem or regard, worthy of admiration and respecting their point of view.

Nurse clinicians are expected to act as preceptors to nursing students in the ward and preceptorship has been explained to mean 'the act of training student nurses practically on wards so that they become conversant with the theoretical knowledge they acquired in the classroom (Broadbent et al. 2014). Kirabira (2018) observed that nursing students respect for registered nurses as practitioners was statistically significantly associated with their involvement in clinical teaching. It should be noted that staff nurses who consider student nurses as part of the nursing team are more likely going to offer their knowledge whereas those who do not, will not willingly be involved in clinical teaching and supervision (Atakro \& Cross, 2016).

The attitudes displayed by student nurses influence the extent nurse clinicians relate with them. This implies that if the nursing students disrespect the nurse clinicians, they will certainly not relate well with them and vice versa (Awuah-Peasah et al, 2013). Despite this, there are scarcity of studies that overtly elaborated on nursing students respect or disrespect for nurse clinicians. However, the reverse has been the case for nurse clinicians as there is 
an abundance of studies where student nurses render bitter complaints of nurse clinicians' disrespect towards them which has an impact on their self-esteem. Some of these studies dwelt on the bullying culture, the horizontal violence and discrimination meted out on these students (Mamaghani et al, 2018; Galletta et al, 2017; Jamshidi et al, 2016; Baraz et al, 2015). Signs of bullying according to Mamaghani et al (2018) include; excessive blaming of students over little mistakes, irresponsible staff trying to mock or hassle students by continuously monitoring students without specific reasons, student humiliation for their choice of profession and mistakes they made, students forced to perform basic and routine nursing tasks that were not necessarily educationally relevant. Student nurses have also indicted nurse clinicians of humiliating and treating them as aides, labourers and servants, forcing them to do the work of nursing assistants instead of seeing them as younger, future colleagues (Drateru, 2019; Mamaghani et al, 2018; Galletta, et al, 2017; Altiok \& Üstun, 2013). In addition, Chuan and Barnett (2012) has listed among others; the overload of students in the clinical unit and students being treated like workers as factors that hindered students' learning in the clinical environment and willingness to even attend clinical postings.

Nurse clinician disrespect for student nurses have been reported by various studies particularly among undergraduate student nurses (Atakro et al, 2019; Deepa \& Kandasamy, 2015). According to Atakro et al (2019), student nurses expressed that the nurse clinicians do not like them and considered them disrespectful while some feel that nurse clinicians dislike them from the onset not because they are disrespectful like they claimed but because they happen to be degree nurses. A student expressed "They call us theory nurses, they always say the diploma students know more than us. It is as if we have done something wrong by doing degree" (Atakro et al, 2019). In Deepa and Kandasamy (2015) one of the participants said "I am very anxious about the behaviour of other staff especially staff nurses in the hospital.... They don't like undergraduate students. They will blame us for all the wrong things and will scold us, and will tag us 'disrespectful'. A nurse clinician in Awuah-Peasah et al (2013) expressed "the degree nursing students are very nonchalant and they have this perception when they come to the ward that they know it all" a perception held by $38 \%$ of the nurse clinicians (Awuah-Peasah et al, 2013). This type of perception shared by some nurses would make them constantly believe that degree nurses are the disrespectful sect. A common saying goes, 'respect is reciprocal', it is likely that these negative attitudes and unfair treatment staff nurses display towards student nurses may have formed the basis on how student nurses act and respond to clinical work and how they relate and respect their senior colleagues.

Although there are still nurses who are generally friendly, supportive and concerned about student nurses welfare however, negativity and lack of respect for students by the nursing staff when they enter clinical placements is more prevalent (Mugoh \& Kamau, 2020; Galletta et al, 2017). Esmaeili et al (2014) noted that one of such negative behavior is when nurses reproach students in the presence of patients and other inter-professional students. This demeaning behaviour can demotivate students and reduce their self-confidence and sense of satisfaction with clinical work, thereby making them become pessimistic with the profession. Aragaw et al (2019) observed that the odds of having a positive attitude towards clinical work was 2 times higher among students who had good communication with clinical staffs compared to their counterparts with negative nurse clinician student relationship.

\section{Conclusion}

There is overwhelming evidence from literature supporting the negative attitude of nursing students in the clinical environment which is detrimental to acquisition of nursing skills. Report from this review indicate that there is a high rate of unauthorized student nurse absenteeism in the clinical areas and majority of the nursing students reported late to clinical work. When nursing students are not punctual, they miss out on privileged opportunity to observe and perform some of the clinical procedures carried out on the patients by the health care team. In spite of this, the reviews noted that majority of the nursing students showed willingness to carry out nursing procedures and were dedicated to their work. However, some displayed nonchalant attitude to clinical work as they consider nursing task stressful, anxiety provoking and demeaning, making them exhibit poor professional attitude evident in their communication/relationship with clients, senior colleagues and peers in other professions. Relationships in the clinical areas tend to uphold medical students as superior compared to student nurses. This tends to arouse feelings of professional inferiority resulting in inability to ask questions during general ward rounds even when they are present. Most student nurses have also accused their seniors of disrespecting them as they are forced to perform basic and routine nursing tasks that are not educationally relevant. 


\section{Recommendations}

Based on the finding reviewed, it is pertinent that nursing students be psychologically prepared in the schools before exposure to the clinical environment. They should be properly oriented in their various institutions about what is expected of them in the clinical learning environment before being posted for clinical work. It is necessary that they understand the dangers of absenting themselves and reporting late to clinical duties. There should be collaboration between faculty members, nurse managers, instructors and nurse clinicians to ensure strict monitoring and supervision of students. Faculty members and clinicians should increase efforts towards building students' self-esteem and professional self-concept through positive relationship/communication to minimize students' feelings of inferiority. Nursing students should be fully equipped with a vast variety of nursing procedures taught and practiced in their demonstration rooms to boost their morale and confidence in the wards. Furthermore, senior nurses should receive periodic in service training on how to relate with student nurses as there is need to focus on building a smooth working collegial relationship which should be hinged on mutual respect, support and regard for themselves as co-professionals. Finally, social interaction opportunities such as the inter-professional education (IPE) should be infused into the curriculum to bridge the chasm between nursing students and other inter-professional students.

\section{Implication to Nursing Education}

- Nurse educators should make available adequate qualified personnel who would train, guide and supervise nursing students when they are being posted to the clinical learning environment.

- Welfare resources and educational facilities such as resting \& dressing rooms, library, internet, training classes etc. should be made available for nursing students in the clinical learning environment.

- Nurse educators should advocate for the compulsory introduction of Inter-professional Education (IPE) course into the already existing curriculum.

\section{References}

Abdelrahman, S. M., \& Abdelkader, A. M. (2017). The influencing factors of absenteeism among nursing students. Journal of Nursing Education and Practice, 7(10), 64-69. https://doi.org/10.5430/JNEP.V7N10P64

Agu, G. U. (2017). Factors affecting clinical training of nursing students in selected nursing educational institutions in Enugu and Ebonyi states of Nigeria. Doctoral dissertation. Retrieved from Http://Www.Unn.Edu.Ng/Publications/Files/Pdf

Aragaw, Y., Sinishaw, W., Daba, W., \& Mekie, M. (2019). Attitude of nursing and midwifery students towards clinical practice and its associated factors in Northwest Ethiopia: a cross-sectional study. BMC Research Notes, 12(1), 205. https://doi.org/10.1186/s13104-019-4230-3

Aseye Kasu, P. (2014). Challenges in controlling lateness, absenteeism and labour turnover. A case study of Christ Apostolic University College, Kwadaso, Kumasi. Doctoral dissertation. Retrieved from http://dspace.knust.edu.gh〉PhilipineAseyeKasupdf

Atakro, C. A., \& Gross, J. (2016). Preceptorship versus clinical teaching partnership: literature review and recommendations for implementation in Ghana. Advances in Nursing, 5. https://doi.org/10.1155/2016/1919246

Atakro, C. A., Armah, E., Menlah, A., Garti, I., Addo, S. B., Adatara, P., ... Boni, G. S. (2019). Clinical placement experiences by undergraduate nursing students in selected teaching hospitals in Ghana. $B M C$ Nursing, 18(1), 1. https://doi.org/10.1186/s12912-018-0325-8

Awuah-Peasah, D., Sarfo, L. A., \& Asamoah, F. (2013). The attitudes of student nurses toward clinical work. International Journal of Nursing and Midwifery, 5(2), 22-27. https://doi.org/10.5897/IJNM12.017

Baraz, S., Memarian, R., \& Vanaki, Z. (2015). Learning challenges of nursing students in clinical environments: A qualitative study in Iran. Journal of Education and Health Promotion, 4, 52. https://doi.org/10.4103/2277-9531.162345

Bjørk, I. T., Berntsen, K., Brynildsen, G., \& Hestetun, M. (2014). Nursing students' perceptions of their clinical learning environment in placements outside traditional hospital settings. Journal of Clinical Nursing, 23(19-20), 2958-2967. https://doi.org/10.1111/jocn.12532

Broadbent, M., Moxham, L., Sander, T., Walker, S., \& Dwyer, T. (2014). Supporting bachelor of nursing students within the clinical environment: Perspectives of preceptors. Nurse Education in Practice, 14(4), 403-409. 
https://doi.org/10.1016/j.nepr.2013.12.003

Chuan, O. L., \& Barnett, T. (2012). Student, tutor and staff nurse perceptions of the clinical learning environment. Nurse Education in Practice, 12(4), 192-197. https://doi.org/10.1016/j.nepr.2012.01.003

Chukwu, E. O., Yakubu, N. H., Haruna, H., Hamina, D., Chia, T., Fiase, T., ... Iornengen, E. (2017). Absenteeism among nursing students: A case study at University of Maiduguri, Borno State, Nigeria. International Journal of Management and Fuzzy Systems, 3(4), 46-51. https://doi.org/10.11648/J.IJMFS.20170304.12

Clucas, C., \& Chapman, H. M. (2014). Respect in final-year student nurse-patient encounters-an interpretative phenomenological analysis. Health Psychology and Behavioral Medicine: An Open Access Journal, 2(1), 671-685. https://doi.org/10.1080/21642850.2014.918513

College of Nurses of Ontario. (2018). Defining Procedures. Retrieved from https://www.cno.org/en/learn-about-standards-guidelines/educational-tools/ask-practice/defining-procedures/

Crouch, S., Fillmore, L., Fly, L., \& Ukot, E. (2015). Impact of inter-professional education on nursing student outcomes in the online environment. American Journal of Health Sciences (AJHS), 6(2), 101-110. https://doi.org/10.19030/ajhs.v6i2.9499

Debyser, B., Grypdonck, M. H., Defloor, T., \& Verhaeghe, S. T. (2011). Involvement of inpatient mental health clients in the practical training and assessment of mental health nursing students: Can it benefit clients and students?. Nurse Education Today, 31(2), 198-203. https://doi.org/10.1016/j.nedt.2010.06.001

Deepa, K. D., \& Kandasamy, M. (2015). Clinical environment: experiences of undergraduate student nurses. International Journal of Advances in Nursing Management, 1(1), 25-30. Retrieved from https://www.academia.edu/15001634/Clinical_Environment_Experiences_of_Undergraduate_student_nurses

Drateru, K. C. (2019). Challenges experienced by student nurses during skill acquisition at the clinical area. Nur $\begin{array}{lllll}\text { Primary } & \text { Care, } & \text { 3(3), } & \text { Retrieved } & \text { from }\end{array}$ https://www.scivisionpub.com/pdfs/challenges-experienced-by-student-nurses-during-skill-acquisition-at-th e-clinical-area-744.pdf

Edwards, D., Burnard, P., Bennett, K., \& Hebden, U. (2010). A longitudinal study of stress and self-esteem in student nurses. Nurse Education Today, 30(1), 78-84. https://doi.org/10.1016/j.nedt.2009.06.008

Esmaeili, M., Cheraghi, M. A., Salsali, M., \& Ghiyasvandian, S. (2014). Nursing students' expectations regarding effective clinical education: a qualitative study. International Journal of Nursing Practice, 20(5), 460-467. https://doi.org/10.1111/ijn.12159

Faiza, A. N. (2015). Prevalence and factors contributed to absenteeism among nursing students at Faculty of Nursing Sciences, University of Khartoum-Sudan. International Journal of Medical and Health Sciences, 4(4), 408-413. Retrieved from http://khartoumspace.uofk.edu $>$ bitstream $>$ handle $>1 \ldots$ pdf

Galletta, M., Portoghese, I., Gonzales, C. I. A., Melis, P., Marcias, G., Campagna, M., .. Sardu, C. (2017). Lack of respect, role uncertainty and satisfaction with clinical practice among nursing students: the moderating role of supportive staff. Acta Bio Medica: Atenei Parmensis, 88(Suppl 3), 43-50. https://doi.org/10.23750/abm.v88i3-S.6613

Jamshidi, N., Molazem, Z., Sharif, F., Torabizadeh, C., \& Najafi Kalyani, M. (2016). The challenges of nursing students in the clinical learning environment: A qualitative study. The Scientific World Journal, 7. https://doi.org/10.1155/2016/1846178

Kapucu, S., \& Bulut, H. (2011). Turkish nursing students' views of their clinical learning environment: A focus group study. Pak J Med Sci, 27(5), 1149-1153. Retrieved from http://pjms.com.pk>pjms>article>download.pdf

Kirabira, A. O. (2018). Factors influencing the involvement of preceptors in clinical teaching of student nurses in training hospitals in Masaka district. Doctoral dissertation, International Health Sciences University.

Kok, G., Guvenc, G., \& Kaplan, Z. (2018). Nursing students knowledge, attitude and willingness to care towards people with HIV/AIDS. International Journal of Caring Sciences, 11(3), 1697. Retrieved from https://www.researchgate.net/publication/338454180_Nursing_Students'_Knowledge_Attitudes_and_Willin gness_to_Care_Toward_People_with_HIVAIDS

Koushali, A. N., Hajiamini, Z., \& Ebadi, A. (2012). Comparison of nursing students' and clinical nurses' attitude toward the nursing profession. Iranian Journal of Nursing and Midwifery Research, 17(5), 375-380. 
Retrieved

from

https://applications.emro.who.int/imemrf/Iran_J_Nurs_Midwifery_Res/Iran_J_Nurs_Midwifery_Res_2012 _17_5_375_380.pdf

Lapeña-Moñux, Y. R., Cibanal-Juan, L., Orts-Cortés, M., Maciá-Soler, M., \& Palacios-Ceña, D. (2016). Nurses' experiences working with nursing students in a hospital: a phenomenological enquiry. Revista Latino-Americana de Enfermagem, 24, e2788. https://doi.org/10.1590/1518-8345.1242.2788

Magobolo, G. N., \& Dube, B. M. (2019). Factors influencing high absenteeism rate of student nurses in clinical areas at a nursing college in the Lejweleputswa District. Curationis, 42(1), 1-6. https://doi.org/10.4102/curationis.v42i1.1985

Mamaghani, E. A., Rahmani, A., Hassankhani, H., Zamanzadeh, V., Campbell, S., Fast, O., ... Irajpour, A. (2018). Experiences of Iranian nursing students regarding their clinical learning environment. Asian Nursing Research, 12(3), 216-222. Retrieved from https://www.asian-nursingresearch.com/action/showPdf

McMahon, M. (2020). What are nursing procedures? Retrieved from https://www.wisegeek.com/what-are-nursing-procedures

Middlesex University. (2011). Attendance (Pre-registration Nursing and Midwifery) policy. School of Health and Social Sciences Institute of Nursing and Midwifery.

Mlek, M. (2011). Nursing students' learning experiences in Clinical settings: Stress, anxiety and coping. Doctoral dissertation, Concordia University. Retrieved from https://spectrum.library.concordia.ca/7372/1/Mlek_MA_S2011.pdf

Mossop, M., \& Wilkinson, T. (2006). Nursing education in gerontological clinical settings: what do elderly patients think of student-rendered care?. Journal of Gerontological Nursing, 32(6), 49-55. https://doi.org/10.3928/00989134-20060601-08

Mugoh, E. K. N., \& Kamau, M. W. N. (2020). Influence of students perception/staff attitude in the clinical areas on student's learning in mathare teaching and referral hospital, Nairobi, Kenya. American Journal of Nursing Science, 9(2), 47-54. https://doi.org/10.11648/j.ajns.20200902.11

Mukumbang, F. C., \& Adejumo, O. (2014). Patients' experiences of being nursed by student nurses at a teaching hospital. $\quad$ Curationis, $37(1), \quad 01-10 . \quad$ Retrieved from http://www.scielo.org.za/scielo.php?script=sci_arttext\&pid=S2223-

Nabolsi, M., Zumot, A., Wardam, L., \& Abu-Moghli, F. (2012). The experience of Jordanian nursing students in their clinical practice. Procedia-Social and Behavioral Sciences, 46, 5849-5857.

Natan, M. B., Zilberstein, S., \& Alaev, D. (2015). Willingness of future nursing workforce to report for duty during an avian influenza pandemic. Research and Theory for Nursing Practice, 29(4), 266-275. https://doi.org/10.1891/1541-6577.29.4.266

Nawaz, K., Hussain, M., Hajra Sarwar, M. A., \& Gilani, S. A. (2018). Determine the factors influencing absenteeism among nursing students. Journal of Health, Medicine and Nursing, 50.

Oner Altiok, H., \& Ustun, B. (2013). The stress sources of nursing students. Educational Sciences: Theory and Practice, 13(2), 760-766. Retrieved from https://files.eric.ed.gov>fulltext

Prentice, D., Engel, J., Taplay, K., \& Stobbe, K. (2015). Interprofessional collaboration: The experience of nursing and medical students' inter professional education. Global Qualitative Nursing Research, 2, 2333393614560566. Retrieved from https://core.ac.uk/download/pdf/62647693.pdf

Rajeswaran, L. (2016). Clinical experiences of nursing students at a selected institute of health sciences in Botswana. Health Science Journal, 10(6), 1. Retrieved from https://www.hsj.gr/medicine/clinical-experiences-of-nursing-students-at-a-selected-institute-of-health-scien ces-in-botswana.php?aid $=17882$

Singh, P. (2015). Causes and effect of student nurses absenteeism at the KwaZulu-Natal College of nursing. Doctoral dissertation. Retrieved from https://ir.dut.ac.za/bitstream/10321/1405/1/SINGHP_2015.pdf

South African Nursing Council. (2013). Regulations relating to the approval of and the minimum requirements for the education and training of a learner leading to registration in the categories professional nurse and midwife. Government Notice No. R. 174. Retrieved from https://www.sanc.co.za/regulat/Reg-cpn.htm

Sumiyoshi, T., Yokono, T., Kawachi, I., \& Suzuki, T. (2020). Learning outcomes of inter-professional 
collaboration among medical and nursing students in Japan. Journal of Interprofessional Education \& Practice, 21, 100377. https://doi.org/10.1016/j.xjep.2020.100377

Tiwaken, S. U., Caranto, L. C., \& David, J. J. T. (2015). The real world: Lived experiences of student nurses during clinical practice. International Journal of Nursing Science, 5(2), 66-75. https://doi.org/10.5923/j.nursing.20150502.05

Visser, C. L., Ket, J. C., Croiset, G., \& Kusurkar, R. A. (2017). Perceptions of residents, medical and nursing students about Interprofessional education: a systematic review of the quantitative and qualitative literature. BMC Medical Education, 17(1), 77. https://doi.org/10.1186/s12909-017-0909-0

\section{Copyrights}

Copyright for this article is retained by the author(s), with first publication rights granted to the journal.

This is an open-access article distributed under the terms and conditions of the Creative Commons Attribution license (http://creativecommons.org/licenses/by/4.0/). 